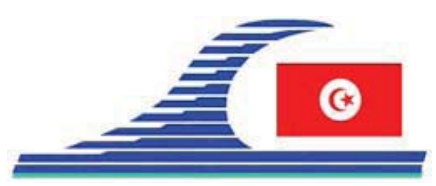

Conférence Méditerranéenne Côtière et Maritime EDITION 1, HAMMAMET, TUNISIE (2009)

Coastal and Maritime Mediterranean Conference

Disponible en ligne - http://www.paralia.fr-Available online

\title{
Une ingénierie culturelle côtière : support d'innovation et d'efficience pour la valorisation des littoraux
}

\section{Odile JACQUEMIN ${ }^{1}$}

1. Urbaniste architecte, docteur en histoire culturelle. Membre du Pôle de compétitivité Mer PACA et du Réseau Français de Recherche Côtière,

Mémoire à lire, territoire à l'écoute (MALTAE), 32 chemin Saint Lazare, 83400 Hyères, France.

odilejacquemin@gmail.com

\section{Résumé :}

Une ingénierie culturelle côtière, support d'innovation et d'efficience pour la valorisation des littoraux. Les thèmes abordés sont :

- L'introduction de l'histoire dans la transdisciplinarité au service de la prospective littorale,

- La culture partagée et l'appropriation par le grand public de la complexité des enjeux et des processus au service d'une meilleure gouvernance.

Nous examinerons notamment l'apport des échanges du XIXe et du XXe siècle entre pays méditerranéens des rives sud et rives nord au travers quatre exemples où lire des manifestations d'innovation et l'émergence de nouvelles pratiques en urbanisme et aménagement du territoire littoral pour questionner les horizons de la coopération du XXIe siècle et proposer une refondation de ses bases sur la réévaluation de la réciprocité.

\section{Mots-clés :}

Méditerranée - Echanges - Urbanisme - Culture - Aménagement du littoral

\section{Introduction}

L'expertise et la diffusion des «bonnes pratiques » est souvent à sens unique, dans un postulat d'une représentation héritière de colonialisme, où les rives nord sont vues comme possédant une expérience dans la protection environnementale du littoral et donc un capital de savoir-faire à exporter.

Nous proposons ici de se pencher sur des échanges entre rives sud et rives nord, avec la volonté délibérée de changer de focale et de point de vue - s'obliger à ne plus orienter le regard et considérer ces échanges comme partie prenante d'une culture méditerranéenne commune, une et indivisible.

Le propos vise à montrer que les apports, en matière d'aménagement du territoire littoral ont été, au cours des XIXe et XXe siècles, dans les deux sens. Ainsi, la

$$
\text { DOI: } 10.5150 / \mathrm{cmcm} .2009 .078-7
$$


réévaluation de la qualité de réciprocité refonde les perspectives de coopération, notamment dans le contexte du changement climatique.

Nous examinerons successivement quatre exemples de l'histoire des échanges entre pays méditerranéens des rives sud et rives nord, parties prenantes de l'histoire de la colonisation / décolonisation, qui ont, chacun dans sa particularité, contribué à un apport d'innovation et à l'émergence de nouvelles pratiques en urbanisme et aménagement du territoire littoral.

\section{Exemples étudiés}

\subsection{L'orientalisme, bien plus qu'une mode et un mouvement artistique}

Dès 1830, le goût pour l'Orient et ses jardins luxuriants de plantes exotiques ont contribué à enrichir le patrimoine paysager de la Côte d'Azur, notamment en matière de plantes d'acclimatation. Les grands jardins de collectionneurs du XIX, comme celui de Thuret à Antibes ou d'Alphonse Denis à Hyères doivent à cet héritage, lui même inscrit dans le mouvement plus large des échanges maritimes, à l'articulation de l'histoire de la marine et de celles des sciences naturelles, dont la médecine et l'étude et la production des plantes médicinales. Indissociable de l'histoire de la conquête d'Alger et des grandes expéditions scientifiques napoléoniennes en Afrique du Nord, cette spécialisation contribue à faire de notre littoral méditerranéen une porte de l'Europe. Au delà de l'exportation des végétaux pour l'acclimatation, palmiers y compris, l'occident apprend de l'orient un certain rapport à la lumière et l'ombre, à l'eau, une mesure des relations de l'intérieur à l'extérieur; l'usage de la céramique et de certains dispositifs spatiaux tels les hammams ou radassières ont contribué à «bonifier» l'habitat provençal et la ville climatique azuréenne, alors en cours de formation.

2.2 L'œuvre de l'urbaniste architecte Prost, le littoral du Var, entre Casablanca et région parisienne

Moins d'un siècle plus tard, à l'horizon des années 1920 et du développement touristique de la côte varoise, le préfet du Var appelle l'architecte Prost, alors en poste auprès du Maréchal Liautey pour concevoir le plan d'urbanisme de Casablanca et autres villes du Maroc. Henri Prost travaille de manière novatrice à un plan d'aménagement de la côte varoise, faisant pour la première fois une œuvre d'urbaniste à l'échelle intercommunale du syndicat des communes de la côte varoise et en développant une consultation des populations et associations, exercice de concertation encore inédit en France métropolitaine.

L'architecte s'appuie sur son expérience en Afrique du Nord où il avait su faire coïncider une vision prospective et l'étude d'un plan régulateur basé sur des valeurs hygiénistes modernes et des préoccupations esthétiques avec la prise en compte des réalités locales et le respect des traditions des populations en place. 
Prost sera ensuite appelé à Paris, où, encore dans un statut de précurseur, il dressera le premier plan d'urbanisme à l'échelle de la Région Ile de France, vingt ans avant la création des régions.

Ce rapide zoom sur l'œuvre de Henri Prost permet deux remarques :

D'une part, l'étude de l'expression de l'urbanisme dans la présence française en Algérie aide à mieux saisir le double visage du colonialisme; il convient de le contextualiser depuis l'héritage saint- simonien et les projets fouriéristes de «jardins d'essai d'organisation sociale et de production » jusqu'aux outils innovants de préservations du patrimoine architectural et urbain. Si l'Afrique du Nord est le lieu symbolique où s'accomplit l'union entre l'Orient et l'Occident, le va et vient d'interactions des deux cultures et terreaux territoriaux fournit une histoire dont la décentralisation et l'actuelle préoccupation de l'échelle du local a encore des enseignements à tirer.

D'autre part, le parcours professionnel de l'homme est en lui même un va et vient qui déconstruit la vision d'une pensée et d'une action venue d'en haut, d'un quelconque pouvoir central; au contraire le frottement à la terre locale fait s'élaborer, par expérimentation, les outils modernes d'un aménagement du territoire visant à concilier protection et développement, héritage et modernité et dont l'aboutissement sera le versement de la capitalisation des expériences d'Afrique du Nord à l'œuvre ultime, le plan régional de la capitale en métropole. De quoi ébranler le schéma de l'exportation de savoir-faire....

\subsection{Capter l'eau}

A partir de la fin des années 1950, le paysage littoral change littéralement de visage avec l'introduction des cultures sous serres dont une des conditions, et non la moindre, est l'accès à l'eau démultiplié par l'usage des forages, qui captent en profondeur et à n'importe quel point de la nappe. Cette nouveauté technique est un des aspects de l'histoire de la colonisation et de la décolonisation. Le rapatriement d'Algérie implique le partage des terres et la valorisation de surfaces restreintes. La technique des forages ouvrant des champs nouveaux, au sens propre et figuré, et marque une rupture dans l'agriculture littorale. Les savoir-faire développés par le Génie des Eaux lors de la valorisation des terres colonisées au XIX siècle réinvestissent en retour le littoral métropolitain, et réorientent radicalement une agriculture traditionnelle de primeurs en plein champs irriguée par puits vers une culture sous-serre intensive. Là encore, c'est, à l'échelle de l'histoire longue, un aller retour d'une rive à l'autre de la Méditerranée.

\subsection{Vivre avec le climat}

Dans les années 1960-1970, un certain nombre d'architectes se réclamant ou non d'une filiation avec le mouvement moderne se retrouvent dans une mouvance que le choc pétrolier confortera sous le nom de « construire avec le climat». 
Loin d'une approche technologique, les démonstrations et expérimentations des projets bâtis valorisent des principes "naturels ». Les dispositifs spatiaux et constructifs qui sont mis en avant pour ventiler et ombrager les quartiers des villes nouvelles sont héritiers d'une tradition méditerranéenne. L'architecte égyptien, Hassan Fathy, se fait mondialement connaître et reconnaître avec son ouvrage " Construire avec le peuple ", variation par extension du « construire avec le climat», et préfiguration du volet social des exigences du développement durable.

Alors que se dessine peu à peu, depuis les années 2000, l'évidence que le climat des rives nord sera celui des rives sud dans une échéance plus brève que la moitié du siècle, les ambitions d'une prospective raisonnée pour nos latitudes sont à construire en tenant compte des leçons à tirer des réalités locales d'Afrique du Nord, en terme d'habitat comme d'agriculture, ou encore de gestion environnementale.

\section{Conclusion}

La mutualisation par des échanges et une capitalisation unique pour fonder une culture commune pour la Méditerranée, autour des enjeux importants de l'adaptation aux changements climatiques et de la gestion de l'eau est une nécessité urgente. Les savoirfaire en la matière s'actualisent tous les jours et imposent innovation et exploration. Il convient, pour avancer «vite» et «juste», de «tordre le coup» au concept d'exportation de savoir-faire occidental entaché de supériorité technologique, pour favoriser les constructions de nouvelles coopérations basées sur l'apport réciproque et le croisement des cultures et des terrains d'expérimentation.

L'enjeu est aussi de reconnaître à la culture et aux génies culturels à inventer une place renouvelée, fondée sur une remise en cause du rapport de l'homme à son milieu et du rapport de l'homme à la technique, et dur apport entre les hommes entre eux. Au croisement des sciences de la nature et des sciences humaines, au croisement aussi d'une visée humaniste à la fois locale et universelle, au croisement enfin des ressources de matière « grise » et des ressources terriennes.

Le remplacement progressif des cultures d'agrumes par les arganiers sur la Côte des Maures et la coopération de formation nouée entre le lycée agricole d'Hyères dans le Var et un établissement de Tunisie en sont un des multiples maillons. 